Postgrad. Med. J. (1966), 42, 661.

\title{
THE OCCURRENCE OF SUBCUTANEOUS EMPHYSEMA IN STATUS ASTHMATICUS
}

\author{
C. J. BulpitT, M.B., B.S. \\ Medical Registrar, Medway Hospital, \\ Gillingham, Kent
}

SubCutaneous emphysema complicating status asthmaticus is rarely seen, but over thirty cases have now been reported in the literature. With severe bronchospasm and air trapping, the alveoli may rupture and air pass along the perivascular sheaths to the mediastinum. A pneumomediastinum is produced with extension of air to the subcutaneous tissues of the neck and chest wall. This mechanism was first demonstrated by Macklin in 1937 by overinflating the lungs of cats. Payne and Geppert found that children and adults are almost equally affected (1961).

The kind of treatment to be employed is of great interest. In surgical decompression the suprasternal notch is explored by blunt dissection and the air released. Schrire and Schrire reported a case which clearly required decompression as a life-saving procedure (1952). McNicholl concluded that operation should be performed when there is weakening of the peripheral circulation (1960). The following case is of interest as she was seriously ill and yet a successful outcome was obtained with conservative treatment alone.

\section{Case Report}

A woman of 34 was admitted in status asthmaticus to the Medway Hospital on 16th April, 1965, under the care of Dr. F. A. Richards. The patient had suffered from severe asthma between the ages of 6 and 15 years. She had pulmonary tuberculosis at the age of 23 , which was successfully treated. Since that age she suffered from only occasional attacks of wheezing. An attack occurred one month before admission and she went into status asthmaticus the day before entering hospital.

On admission she was cyanosed and semiconscious. Her pulse rate was 130 per minute, her blood pressure $160 / 90$ and her temperature $99^{\circ}$. There was subcutaneous emphysema over both sides of the neck and over the upper chest anteriorly and laterally. Expiration was prolonged with much bronchospasm and scattered basal rales. Chest radiograph also showed the presence of subcutaneous emphysema most marked over the right upper chest. (Fig. 1).

The immediate treatment consisted of $0.5 \mathrm{~g}$. aminophylline and $100 \mathrm{mg}$. hydrocortisone hemisuccinate intravenously. The patient was restless and $50 \mathrm{mg}$. promazine were given intramuscularly. Prednisolone was started, $20 \mathrm{mg}$. 6 hourly by mouth. Eight hours later the patient's condition deteriorated. Her pulse rate was 150 per minute and the pulse faded with inspiration. The blood pressure was then 115/70. An intravenous infusion was started with $\mathbf{4 0 0} \mathrm{mg}$. hydrocortisone and $1 \mathrm{~g}$. aminophylline in one litre of dextrosesaline solution. Tetracycline was given, $100 \mathrm{mg}$. intramuscularly every 6 hours. Her condition continued to deteriorate and 13 hours after admission the pulse

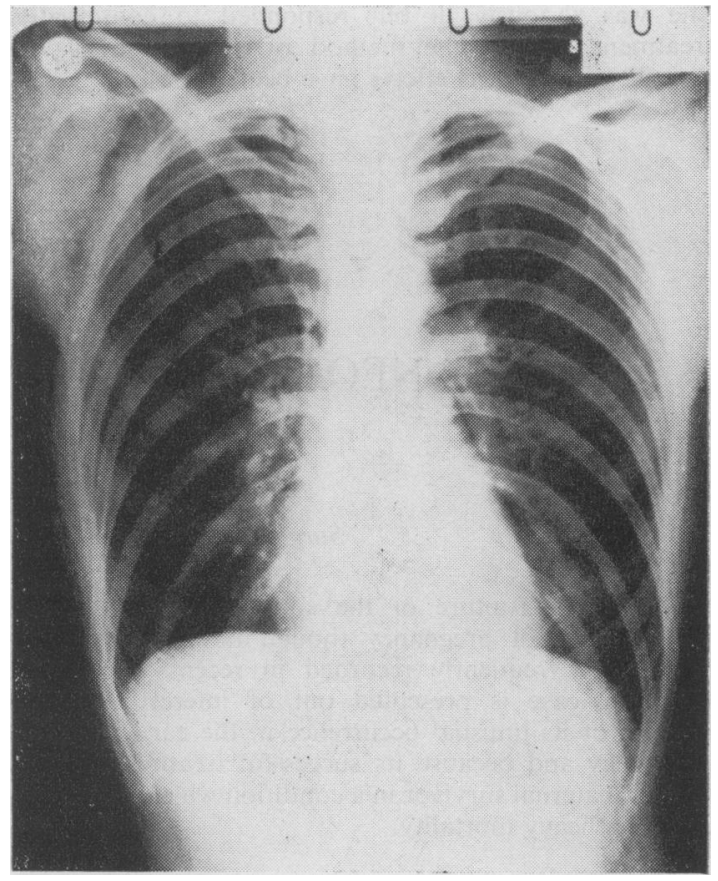

FIG. 1.-Radiograph on admission showing subcutaneous emphysema.

rate was 160 per minute and blood pressure $110 / 60$. At this stage a further $200 \mathrm{mg}$. of hydrocortisone were given intravenously in addition to the drip and $5 \mathrm{ml}$. of paraldehyde intramuscularly. Following this therapy the patient gradually improved. A week later she was free of any bronchospasm and there was no evidence of subcutaneous emphysema. The steroid dosage was gradually reduced. The patient was discharged home well two weeks after admission and when seen in the Out-Patient Department on 26th May, 1965 she was not receiving any treatment and was free of bronchospasm.

\section{Comment}

Inspiration increases lung volume and the size of the pulmonary vascular bed. The simultaneous rise in blood flow to the right heart prevents any weakening of the peripheral circulation. An increased intrathoracic pressure may interfere with this influx of blood to the heart, and produce fading of the pulse with inspiration.

This mechanism was thought to occur in the case 
under discussion. The presence of a pneumomediastinum could have interfered with filling of the right heart, but the successful outcome of conservative treatment indicated that this accumulation of air was a minor problem. The fall in blood pressure was considered to be unrelated to the giving of promazine 8 hours before. McNicholl (1960) pointed out that a lateral chest radiograph shows the amount of air in the mediastinum. This radiograph would have been of assistance in this case.

\section{Summary}

A young woman developed a subcutaneous emphysema of the chest wall during an attack of status asthmaticus. She was seriously ill but responded to conservative treatment alone. The method of production of this complication and its effects have been discussed.
The writer is indebted to Dr. F. A. Richards fe helpful criticism.

\section{REFERENCES}

MaCklin, C. C. (1937): Pneumothorax with Massi年 Collapse from Experimental Local Over Inflation of the Lung Substance, Canad. med. Ass. J. 36, 414.

MCNiCHOLl, B. (1960): Pneumomediastinum an Subcutaneous Emphysema in Status Asthmaticus Requiring Surgical Decompression, Arch. Dis. Childth 35, 389.

Payne, T. W. and Geppert, L. J. (1961): Mediastinä and Subcutaneous Emphysema Complicating Bronchiat Asthma in a Nine-year-old Male. J. Allergy, 32, 13द्2 SCHRIRE, T. and SCHRIRE, X. (1952) : Surgic영 Emphysema in Asthma, S. Afr. med. J., 26, 465.

\title{
SPONTANEOUS RUPTURE OF THE SPLENIC ARTERY IN EARLY PREGNANCY
}

\author{
I. G. Wylie, M.B., B.S. \\ Surgical Registrar, Royal Sussex County Hospital, Brighton 7.*
}

SPONTANEOUS rupture of the splenic artery is a rare complication of pregnancy though its occurrence has been more frequently recorded in recent years. The following case is presented out of interest primarily because of its unusual occurrence in the early stages of pregnancy and because its successful treatment adds a further maternal survivor in a condition which has always carried a heavy mortality.

\section{Case Report}

Miss S. age 19, was admitted as an emergency to Hove General Hospital on September 1st, 1964, at 5.45 p.m. The patient's condition did not allow a detailed history to be obtained, but it was known that she had collapsed 45 minutes before admission and on regaining consciousness, complained of severe colicky pain in the left lower quadrant of the abdomen. Her last menstrual period was at the end of May.

The patient was desperately collapsed and on the verge of unconsciousness. Neither the radial pulse nor the blood pressure could be recorded and the extremities were cyanosed. There were signs of a previous pregnancy.

The abdomen was soft on palpation, but tenderness was elicited in the left flank. No masses were felt. Bowel sounds were absent. Vaginal examination revealed a boggy swelling in the Pouch of Douglas and showed the absence of vaginal bleeding. The uterus was enlarged to the size of a ten-weeks pregnancy and the fornices were acutely tender.

A provisional diagnosis was made of ruptured ectopic pregnancy probably, having regard to the extended period of gestation, interstitial in position.

*Present address: Department of Anatomy, London Hospital, Medical School, London, E.1.
Immediate attention was turned to resuscitation Oxygen was administered by mask and transfusiom commenced with plasma followed by a pint of uE matched O-positive blood which was the only bloged available. The patient responded well to these measuros and by the time arrangements had been completed fô operation, the patient's blood pressure was recorded $90 / 60 \mathrm{~mm} \mathrm{Hg}$.

Operation (J.C.F.L.W.) Commenced 7.45 p.m. The abdomen was opened through a left lower paramediang incision. The peritoneal cavity contained four pints of fresh blood; this was evacuated and the patients condition deteriorated, her blood pressure falling barely recordable levels. The uterus was enlarged pregnancy to a size estimated as being compatible with a 14 week cyesis. Both ovaries and tubes were normád. Normal pelvic findings recalled the possibility of 9 ruptured splenic artery aneurysm and the upper abdomen was examined after extending the incision. A small regt was found in the splenic artery just proximal to the hilum. No aneurysmal dilatation of the vessel wis noted. The spleen appeared normal in size and appea ance. The splenic vessels were clamped and haemorrhage having been controlled, splenectomy was performed? The patient's condition began to improve following arrest of haemorrhage. During operation the patien received by transfusion, two pints of plasma and two pints of cross-matched blood. A further three pints cross-matched blood were given in the next 12 hours. 0

Histology. The section of the spleen itself shows obvious abnormality. Sections of the splenic artey show considerable variation in calibre from one part of the wall and there is quite clear evidence of cystic media necrosis in the thicker areas. This diagnosis is confirment by a special stain for elastic tissue.

Progress. The following day the patient felt wet 